NOW READY

\title{
THE ACOUSTIC METHOD
}

For the Training of the Deaf and Hard-of-Hearing Child By MAX A. GOLDSTEIN, M.D., LL.D.

This Volume contains 244 pages; 50 illustrations

Textile Leather (Waterproof) Binding $\$ 3.00$ Postage Prepaid

Twelve chapters, including Evolution of the Acoustic Method - Definition and Principles of the Acoustic Method - The Practice of the Acoustic Method The Pupil: (1) The Deaf Child; (2) The Hard-of-Hearing Child; (3) The PreSchool Deaf Child - The Teacher - Case Recording - Tests of Hearing Audiometers - The Audiogram - Hearing Aids - Tactile Training Anatomy of the Ear.

Published by THE LARYNGOSCOPE PRESS 640 South Kingshighway

St. Louis, Mo.

\section{BINDING}

\section{Journal of Laryngology \& Otology}

Subscribers wishing to have their Journals bound can do so by sending them to the Publishers.

Volumes are strongly bound in whole dark blue buckram cases, with gold lettering on spine. The cost of binding is $15 s$. per volume, including postage.

Missing parts can be supplied at $4 \mathrm{~s}$. each, or the whole volume, complete in the above binding, for 50 s.

Publishers' cases can be supplied for 5 s.

HEADLEY BROTHERS, IO9 KINGSWAY, LONDON, W.C.2

Please mention The Journal of Larygology when replying to advertisements 


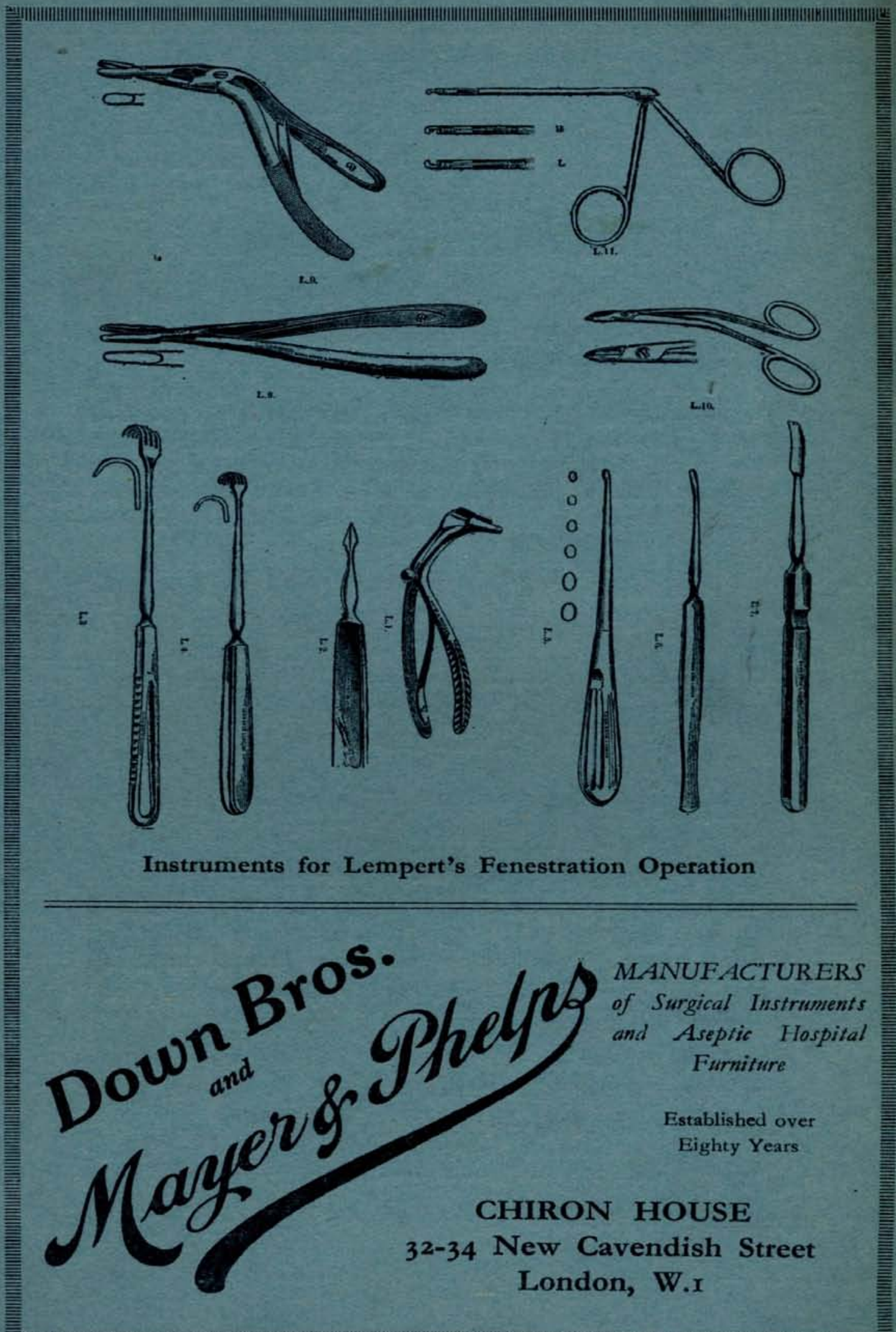

จำ Printed and published for the proptietors by Headiey Brothers, 209 Kingsway, London W.C.2, and Ashford, Kent 